\title{
The Philippine Spotted Deer Conservation Project
}

\author{
William L. R. Oliver, C. Roger Cox and Louella L. Dolar
}

The Philippine spotted deer Cervus alfredi, endemic to the Visayan Islands, is threatened by deforestation and hunting. Already extinct over 95 per cent of its former range, populations survive probably only in Panay and Negros. In 1987 a conservation programme was drawn up with two immediate objectives: to establish a national park in west Panay and to embark on a captive-breeding programme. The authors describe the operation of the project and its progress to date, and discuss plans for its extension.

\section{Introduction}

Until quite recently, the Philippine spotted or Prince Alfred's deer Cerous alfredi remained extremely poorly known. Indeed, it was effectively lost as a recognized form by being classified as a regional variant of the widespread and diverse group of sambar deer, C. unicolor, which also included the Philippine rusa $C$. mariannus. However, in their recent review of the taxonomy of the Philippine deer, Grubb and Groves (1983) recognized C. mariannus and $C$. alfredi as separate species; the former having at least four subspecies endemic to the islands of Luzon, Mindoro, Mindanao and associated smaller islands in the east Philippines, and the latter a highly distinct, monotypic form, endemic to the Visayan Islands, central Philippines.

The survival of both of these deer, and that of the third endemic species, the Calamian deer Cerous calamianensis, which is found only on a few of the larger islands of the Calamian group, is threatened by profligate deforestation and, despite full legal protection, intense hunting pressure. Thus, the Calamian deer is recognized both nationally and internationally as a seriously threatened form, and is accorded Vulnerable status in the International Red List of Threatened Animals (IUCN, 1988, 1990). C. mariannus is not yet considered seriously threatened throughout its range, and is not included in the IUCN Red List. However, it is certain that at least one subspecies, C. $m$. barandanus, is at some risk over its restricted. range in Mindoro, and the present status of some other forms, such as C. m. nigricans, from lowland Mindanao, needs to be investigated. By comparison, the spotted deer is unquestionably highly threatened, because it has already been extirpated over most of its known former range in the larger islands of the Negros Faunal Region of the central Philippines, which comprises the larger, western section of the Visayas geopolitical region (Figure 1).

\section{The current status of Cervus alfredi}

The extent of the decline of the Philippine spotted deer was not fully appreciated until 1985, when a 3-month field-status survey was conducted by one of us (Cox, 1985, 1987a). This survey revealed that the species was already extinct over most of its former range, including all Cebu, Siquijor and Guimaras, and that it survived in only one small area of western Panay (namely: Mt Baloy-Mt Madjaas) and in a few scattered fragments of remaining forest on Negros. It is likely that the species is also extinct on Masbate, which has been almost completely deforested, although this area was not visited during the 1985 survey. Deer are also now extinct on Bohol, though it remains unclear whether $C$. alfredi or 


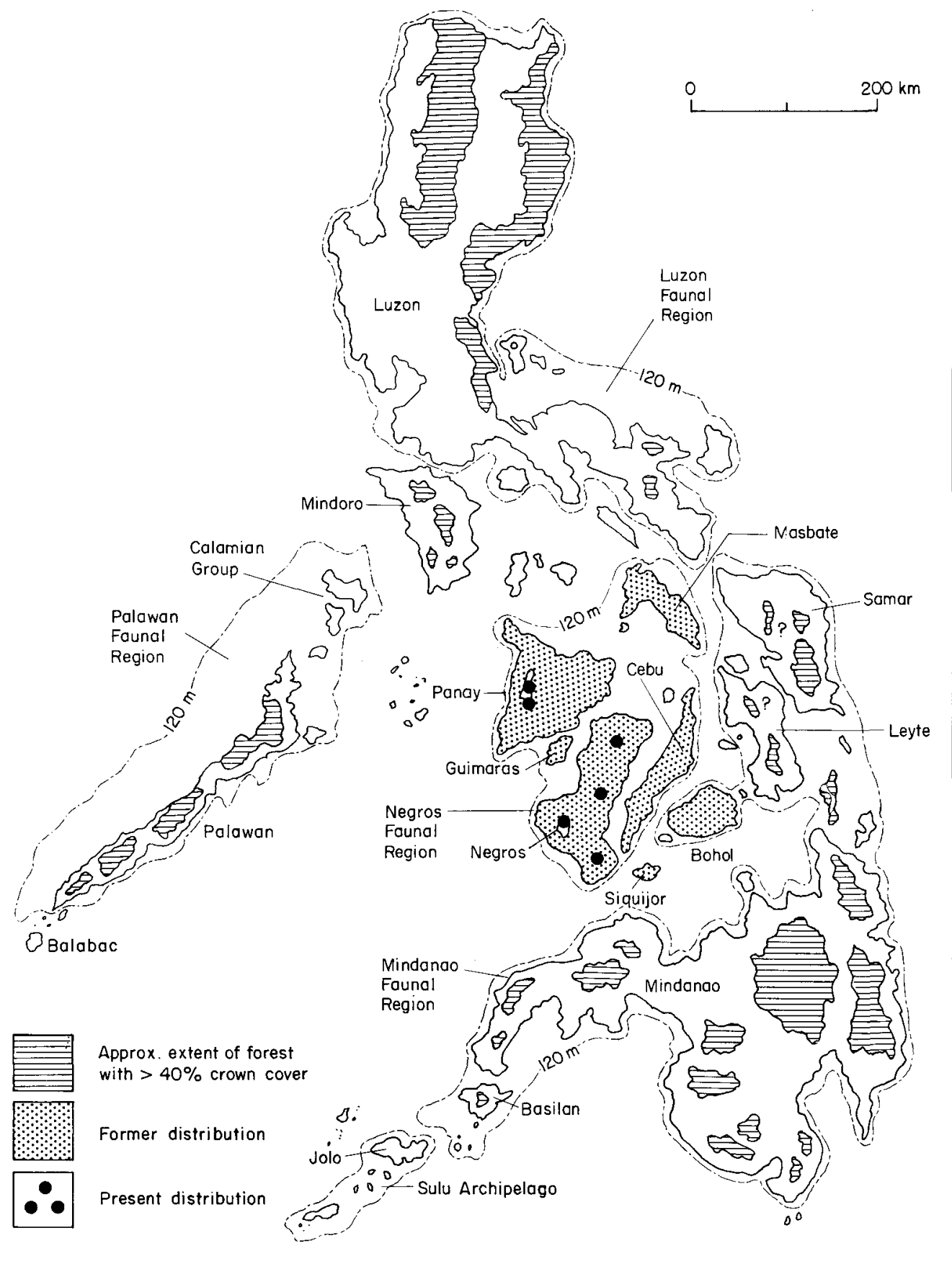

Figure 1. Approximate former and present distribution of the Philippine spotted deer Cervus alfredi. Forest cover data is modified after Revilla (1986), and the division of the archipelago into separate faunal regions, as indicated by the 120 -m bathymetric line, follows Heaney (1986). See text for further explanation. 


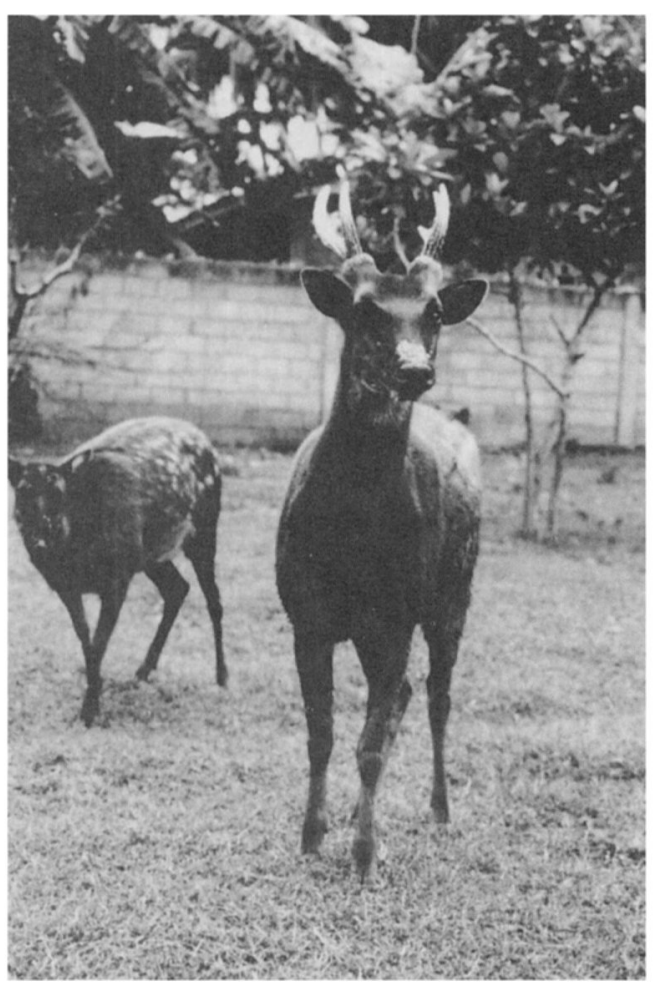

An adult pair of Philippine spotted deer Cerrus alfredi (Lawrence Heaney).

C. mariannus formerly occurred there because this island actually forms part of the Mindanao Faunal Region, as defined by Heaney (1986) on the basis of the 120-m bathymetric line (Figure 1). Reports of deer occurring on the larger, neighbouring islands of Samar and Leyte were also assumed to refer to C. alfredi, rather than $C$. mariannus, during the 1985 survey (Cox, 1985, 1987a), although these islands also form part of the Mindanao faunal region. Moreover, as C. mariannus is now known to occur on both of these islands, it now seems likely that $C$. alfredi is absent, at least as a native or pure-bred form. As a result, the species is believed to have been extirpated over at least 95 per cent of its former range, and to survive only as a series of small, discrete and highly vulnerable populations on no more than two islands, Panay and Negros.

Commensurate with the findings and recommendations of the 1985 survey, the species was included for the first time in the 1988 Red
List of Threatened Animals (IUCN, 1988), when it was accorded Endangered status; thereby denoting the probability of its extinction in the near future if the causal factors, habitat attrition and hunting pressure, continue to operate. In a recent world-wide review of conservation priorities, the IUCN Deer Specialist Group (in litt.) concluded that $C$. alfredi was one of the most seriously threatened of all species of deer.

\section{Protocol for the conservation programme}

In the interim, the findings of the 1985 field survey were presented to the relevant authority in the Philippines, the Protected Areas and

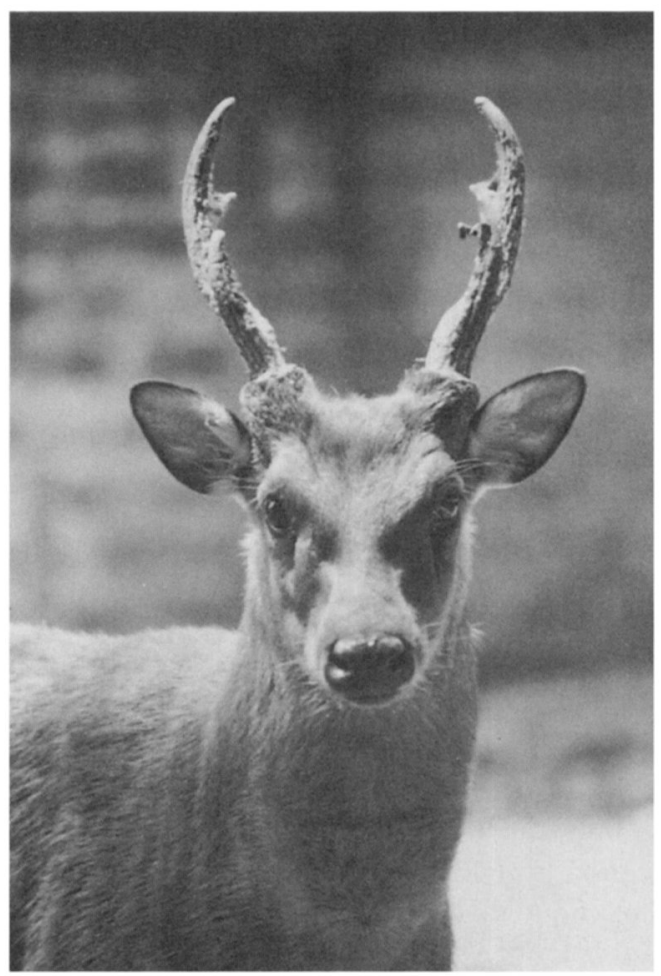

The Philippine rusa Cerous mariannus remains relatively widely, but now patchily, distributed throughout the larger, eastern Philippine islands. Some races are almost certainly threatened by continued deforestation and hunting pressure (William Oliver). 


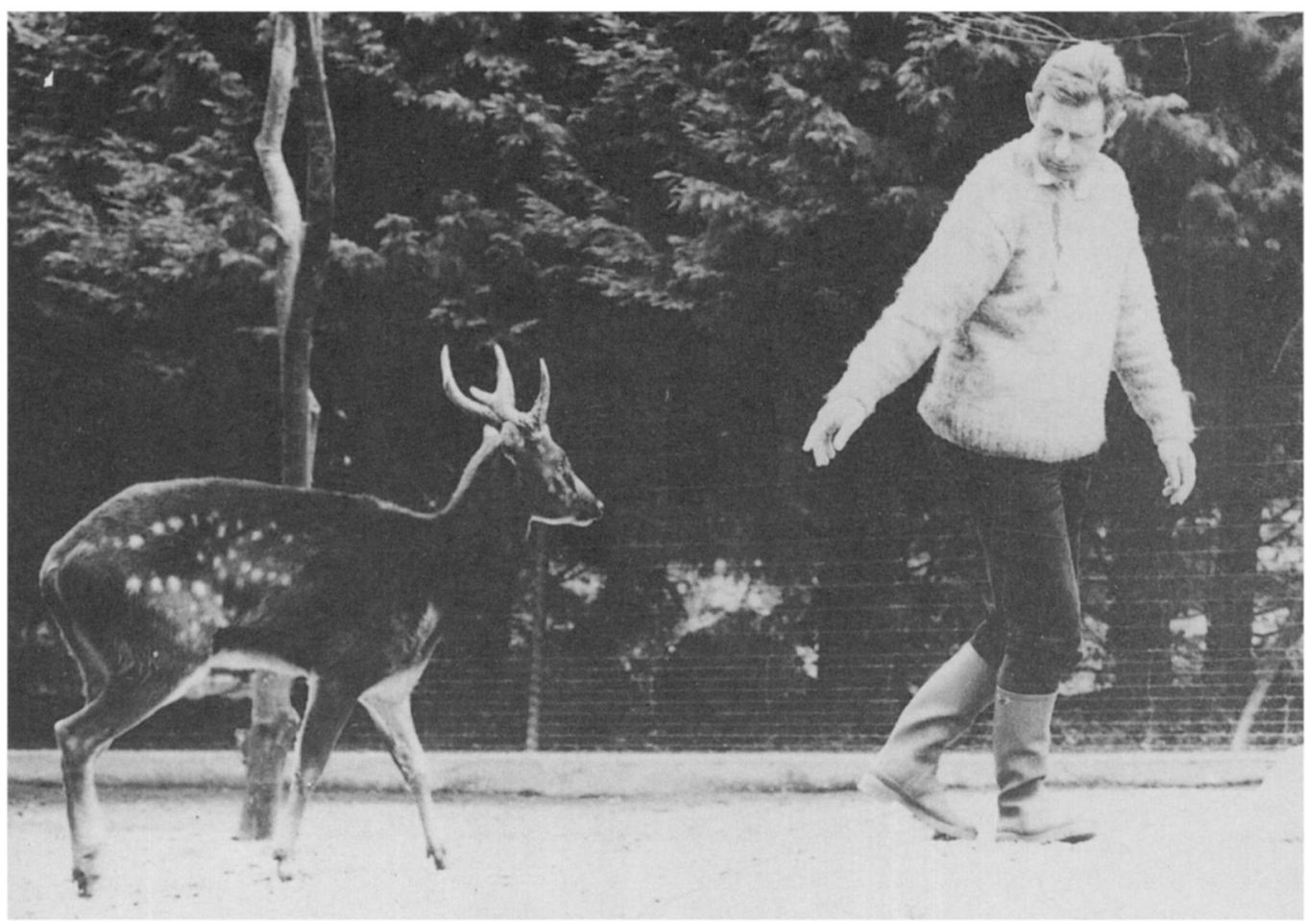

An adult male Philippine spotted deer in Mulhouse Zoo (Claude Thouvenin).

Wildlife Bureau (PAWB) of the Department of Environment and Natural Resources (DENR). As a result, two priority recommendations for immediate conservation action were agreed. These were: (i) that a new national park be created to protect the sole remaining (and single largest) wild population of spotted deer in the Mt Baloy-Mt Madja-as area of west Panay; and (ii) that a properly structured, international co-operative captive-breeding programme be established. In order to execute and finance these projects, the first formal international agreement for a species conservation programme in the Philippines was drafted and signed by DENR and the Parc Zoologique et Botanique de la Ville de Mulhouse (Mulhouse Zoo), France, in April 1987. Under the terms and conditions of this agreement (which was modified in May 1990 in accordance with the development of a new breeding-loan policy by DENR, the 'Philippines Wildlife Loan Agreement' or PWLA, which now applies to all threatened species of wildlife legally exported from the Philippines), it was recognized that the DENR had insufficient resources for the implementation of the proposed conservation strategy and that much of the necessary funding would have to be obtained from outside agencies. To this end, the Zoologischer Garten Berlin (West Berlin Zoo) provided funding for a survey and development of a management plan for the proposed new national park on Panay. This project, which was conducted over a 4-month period in 1986/1987 by a team of Filipino and foreign scientists, resulted in plans for the development of 40,000 ha of forest as the new Panay Mountains National Park (Cox, 1987b). Further work on this proposal is currently being undertaken by the relevant regional authorities of DENR (C. Magno, pers. comm.), but it is hoped that the new park will be established by Presidential Decree and officially gazetted in the near future (W. Dee, pers. comm.).

At the same time, efforts were being made 
to raise the necessary finance for the development of the captive-breeding programme. Under the terms of the PWLA with the Mulhouse Zoo, it was proposed that this include the establishment of both local and international breeding stocks through the aegis of similar loan agreements between all participating institutions and the DENR. All of the animals acquired for this programme (the 'founders') would therefore be 'loaned' to the project by the Government of the Philippines and managed co-operatively as a basis for the establishment of a 'World Herd'. The title of all ensuing captive-bred progeny would also remain with the 'Government and People of the Philippines' under the terms of the umbrella Agreement between DENR/PAWB and the Mulhouse Zoo, thereby enabling the future management of this stock in the best interests of the species and precluding the possibility of it being involved in any commercial trade.

In order to assist the development and monitoring of the breeding programme, and to advise on the placing of breeding stocks with other reputable breeding centres in the Philippines and elsewhere, a 'Philippine Spotted Deer Conservation Committee' was also established under the terms of the umbrella Agreement. The terms of reference of this Committee, which currently comprises three Filipino and three foreign members, also empower it to negotiate the donation of funds from any institution outside the Philippines that may become directly involved (as an extension to the breeding programme) through its receipt of any spotted deer under the aegis of the Agreement.

By this means it is hoped to generate periodic, but possibly substantial, sums of money for the perpetuation of the programme, and the initiation of other conservation activities in the Visayan region. These activities will include various conservation education and biological research projects, to be focused largely on this species, which should be initiated in the near future. In this context, the spotted deer is a potentially ideal 'flagship' for increased conservation interest and activity in the Visayas, because it is the largest and one of the most attractive animal species endemic to this region, as well as being one of the most endangered. This standpoint is manifest in the attempt to set up the proposed Panay Mountains National Park, which is intended to protect the most important remaining tract of forest in the Visayas and one of the most important tracts anywhere in the Philippines. Similarly, the captive-breeding programme is not only intended to be an integral part of a wider conservation strategy centred on this species, it has also been deliberately structured to assist the promotion and funding of that strategy.

\section{The captive-breeding programme}

The captive-breeding programme was finally launched in February 1990, in collaboration with the Department of Biology and the Centre for Tropical Studies (CENTROP) of Silliman University, in Dumaguete City, Negros Oriental, and with funding from the Mulhouse Zoo and San Diego Zoological Society. A preliminary survey of spotted deer held in captivity on Negros and Panay (as well as those originating from these islands but

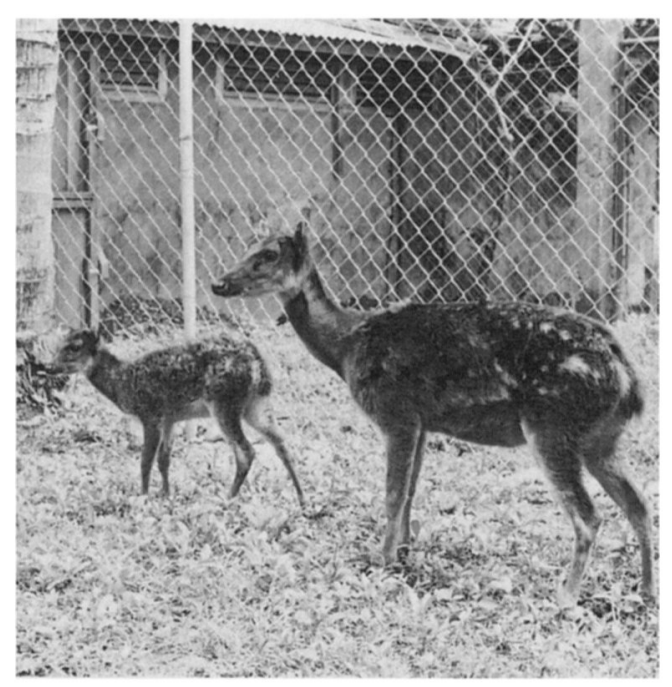

A female Philippine spotted deer with a 3-month old captive-born calf at Silliman University, Dumaguete City (William Oliver). 
held on Cebu and in Manila) was conducted in March 1990. A total of 36 (17 males, 16 females and three unsexed) C. alfredi held by private owners in 17 separate locations was identified, though only 13 (three males, seven females and three unsexed) or 36 per cent were captive-bred. As far as could be ascertained, all of these animals were either of pure Negros (nine males, four females and three unsexed) or Panay (i.e. six males, six females) origin, though at least eight C. alfredi $\times$ C. marianus hybrids were seen in three separate locations elsewhere on Negros and Cebu (Oliver and Cox, 1990a, b).

The primary objective of this survey was to investigate the feasibility of acquiring as many of these animals as possible for the captivebreeding programme, thus reducing the number of individuals that would have to be obtained from the wild. In the event, the response received from the majority of private owners was most encouraging, for all but one of these owners agreed to release some or all of their animals to the project, even though few of these people had any prior intention of disposing of their 'pets'. By this means, a total of 21 (10 males, 11 females) from 12 separate owners were acquired for the project, although three (one male, two females) of these animals proved to be in extremely poor condition and have since died. Of this total, 16 (eight males, eight females) or 73 per cent were received as outright donations, while the remainder were obtained by purchase (two males, one female) or exchange (one male, two females); the latter for a trio of fallow deer (Dama dama) obtained from the Ninoy Aquino Nature Centre in Quezon City, and donated to the project by DENR for this purpose.

All of the surviving spotted deer are of known origin, having been wild-caught (or captive bred from wild-caught parents) on Panay (three males, four females) or Negros (five males, five females). Because these islands have been separated for thousands of years, it was considered essential to maintain the genetic integrity of the two stocks-or to do so at least until such time as the degree of differentiation between them had been properly assessed. As a result, two local breeding projects were established-one each on Panay (at Bitu Farm in Barangay Gutao, Iloilo Province) and on Negros (at Silliman University in Dumaguete City). In addition, seven (three males, four females) animals of Negros origin were exported (on 30 May 1990) on breeding loan to the Mulhouse Zoo to form the basis of a third breeding stock. As the Mulhouse and Silliman herds are of Negros origin, they will be managed as a single breeding population by periodic exchanges of unrelated animals. The three herds will form the basis of the World Herd, which will be managed as two separate (Negros and Panay) breeding stocks on the basis of sound genetic and demographic principles. A studbook is therefore being drawn-up by the Mulhouse Zoo, which will register and document the pedigrees of all founders and their captivebred progeny, and enable the progress of the breeding stocks to be monitored.

Under the terms of the Agreement between DENR/PAWB and the Mulhouse Zoo, a maximum of 12 spotted deer may be exported (on breeding loan) to Mulhouse, so it is hoped to arrange a second shipment of five animals at some later date as additional stock becomes available from the Silliman herd by reproduction and from incidental acquisitions of wildcaught animals. Clearly, one of the many advantages in the establishment of the local breeding centres is that these may also be used to accommodate and accumulate any additional specimens of Negros or Panay origin as may become available in the future by donation, purchase or confiscation. Any such animals will be added to the World Herd, thereby enabling the number of founder individuals to be increased at intervals. Following the export of the Mulhouse animals, for example, another three individuals, all wild-caught on Negros, have been acquired by purchase (one male) or donation (two females) for the Silliman herd, which now stands at seven (four males, three females); the latter including the first captivebred young (a male born in January 1991) produced under the aegis of this programme.

As soon as is practicable, it is hoped to extend this programme by the distribution of small numbers of least-related, captive-bred 
individuals to other reputable breeding centres, both in the Philippines and elsewhere. All such extensions would be made under breeding loan agreements, and the title of those animals would remain with the Government of the Philippines. Whenever possible, the Spotted Deer Conservation Committee will also negotiate the donation of funds from the recipient institutions for specific, related conservation projects in the Visayas region (which should eventually include $C$. alfredi reintroduction projects); thereby involving those institutions in the local, as well as the international, conservation effort.

\section{Acknowledgments}

We are greatly indebted to a large number of individuals and institutions without whose interest and active support this project would not have been possible. We are especially grateful to the various officers of the Department of Environment and Natural Resources in Manila, Iliolo, Bacolod, Dumaguete and Cebu Cities - in particular, Dr Celso Roque, Samuel Penafiel, Carlo Custodio, Wilbur Dee, Marlynn Mendoza, Carlos Magno, Larry Cayayan, Alfred Pintor and Demetrio Kho; and the Department of Biology, College of Agriculture and Marine Laboratory of Silliman University-particularly Professor Felina Tiempo and Dr Ely Alcala. We would also like to thank the various private owners who generously donated animals to this project, including Tommy Que, Mrs Georgina Augustin, Mayor Ramon Jison, Noel Basubas, the Negros Forests and Ecological Foundation and the Rotary Club of Southern Dumaguete. Carmelo Celis, Perla Magsalay, Rogelio Rigor, Ramon Hilado, Bart Lacson, Gerry Ledesma and Nema Tarantan all provided invaluable assistance in various ways, as did Dr Hans Frädrich, Richard Koch, Dr Lawrence Heaney, Anton Sojer, Roland Wirth, Dr James Dolan and Dr Jean-Marc Lernould. We would also like to extend our sincere thanks to the Zoological Society of San Diego, Parc Zoologique et Botanique de la Ville de Mulhouse, the Zoologischer Garten Berlin and the Haribon Foundation, which have provided the majority of funds for this project.

\section{References}

Cox, C.R. 1985. A field survey of the distribution and conservation of the wild pig (Sus barbatus cebifrons) and Prince Alfred's spotted rusa (Cervus alfredi) in the Visayan Islands, Republic of the Philippines. Unpublished report to the IUCN/SSC Pigs and Peccaries Specialist Group, 27pp.

Cox, C.R. 1987a. The Philippines spotted deer and the Visayan warty pig. Oryx, 21, 37-42.

Cox, C.R. 1987b. A preliminary survey of the proposed Panay Mountains National Park. Unpublished report to the Zoologischer Garten Berlin, 44pp.

Grubb, P. and Groves C.P. 1983. Notes on the taxonomy of the deer (Mammalia, Cervidae) of the Philippines. Zool. Anz., Jena 219 (1/2), 119-144.

IUCN 1988. 1988 IUCN Red List of Threatened Animals. Gland, Switzerland.

IUCN 1990. 1990 IUCN Red List of Threatened Animals. Gland, Switzerland.

Heaney, L.R. 1986. Biogeography of mammals of SE Asia: estimates of rates of colonisation, extinction and speciation. Biol. J. Linnean Soc. 28, 127-165.

Heaney, L.R., Gonzales, P.C. and Alcala, A.C. 1987. An annotated checklist of the taxonomic and conservation status of land mammals in the Philippines. Silliman J. 34 (1-4), 32-66.

Oliver, W.L.R. and Cox, C.R. 1990a. The present status of captive Philippine deer, Cervus alfredi and $C$. marianus. Unpublished report to Zoological Society San Diego and the Mulhouse Zoo, 9pp.

Oliver, W.L.R. and Cox, C.R. 1990b. Philippine spotted deer (Cervus alfredi) captive breeding programme: notes on 'World Herd' founders (as of May 1990). Unpublished report to Zoological Society San Diego and the Mulhouse Zoo, 4pp.

Revilla, A.F. 1986. Fifty-year Forestry Development Program for the Philippines. Forestry Development Centre, Los Banos, Philippines.

William L. R. Oliver, Park End, 28a Eaton Road, Norwich, Norfolk NR4 6PZ, UK.

C. Roger Cox, 9 Markham Square, London SW1 $4 U Y, U K$.

Louella L. Dolar, Dept of Biology, Silliman University, Dumaguete City 6200, Negros Oriental, Rep. Philippines. 